\title{
Ornamental Costus ${ }^{(1)}$
}

\author{
DAVE SKINNER (2)*
}

\begin{abstract}
In recent years the spiral gingers (genus Costus) have become more and more popular as ornamental garden plants. Dave Skinner describes these plants, including his approach to identification of New World Costus, corrections to some common identification errors, information about cold hardy species, and information about Costus hybrids and cultivars.
\end{abstract}

Keywords: spiral gingers, Costus, identification

\section{INTRODUCTION}

About 20 years ago I began to focus my gardening interests on gingers, and ultimately on the so-called "spiral gingers" in the plant family Costaceae. I was enthralled by the diversity of flowering forms and colors and the beautiful spiraling architecture of these plants. I soon found there were some species of Costus that grew to 3 meters and more in height, while others such as the African species Costus spectabilis is flat to the ground with a mere height of a few centimeters. In some species the leaves are deep forest green in color with a silvery mid-rib stripe, others are silvery grey, and still others have a dark purple color to the undersides. A few cultivated Costus have variegated leaves with yellow and white stripes or a mosaic pattern.

In some species the bracts have colorful foliacious appendages making a long-lasting inflorescence that many people mistakenly call the "flower". Most Costus typically flower terminally at the top of a leafy stem, while others send up a separate flowering shoot or one with just a few leaves at the base of the plant. Some Costus species flower both ways, terminally and basally. The true flowers of Costus are either tubular shaped in colors of red, yellow or orange; or they have a more open labellum in white, yellow or red.

As with many gardeners I started out by adding to my collections any new plants I could find in mail order sites, plant nurseries, or from friends and acquaintances in garden clubs. My garden is located in the north of Florida where the winter temperatures fall well below freezing, but I did not let that stop me. I grew what I could find that is "root hardy" outdoors and soon added a greenhouse to grow the more tender species.

At first I simply relied upon the plant tags or internet photos to identify the names of the species, but further research revealed that many had been incorrectly identified when first introduced to cultivation, and the errors in some had persisted for many years. I was fortunate that in the 1970's Dr. Paul Maas had published a complete monograph of the neo-tropical species, with an identification key, full descriptions and illustrations.

Then in 2005 I made my first trip to the tropics to see these wonderful plants in the wild growing in their native habitats. I was hooked! I absolutely fell in love with the sights and smells and sounds of the tropical forests and would follow that first trip to Costa Rica with many more trips, at every opportunity, to see these plants in Costa Rica, Panama, Mexico, Colombia, Ecuador, Peru, Guyana and Brazil.

The most important lesson I have learned during these trips is that Nature does not follow our rules for what a given species should look like. It is one thing to see the identical clones of cultivated plants that have been circulated by growers, and quite another to see the diversity of appearance in the wild. Some species that have a wide geographical range will look quite different from one region to another. Costus species also are prone to natural hybridization, and I have seen many examples in the wild where a single plant exhibits characters of two different species that are found growing locally.

\section{IDENTIFICATION OF NEO-TROPICAL COSTUS}

The plant family Costaceae includes other genera besides the genus Costus that is the focus of this article. In New Guinea, other Melanesian islands, and tropical Australia is the genus Tapeinochilos with its colorful and long lasting bracts. From Southeast Asia is the nowseparated genus Cheilocostus (or Hellenia if you accept the recent name change). That genus is best known for the commonly cultivated ornamental garden plant $C$. speciosus. Then there is the small genus Paracostus that is represented by four species in Borneo and one in Africa.

\footnotetext{
(1) Received 08/08/2016 in and accept in 31/10/2016

(2) Le Jardin Ombragé, Tallahassee, Florida, USA. *Corresponding author: dave@gingersrus.com
} 


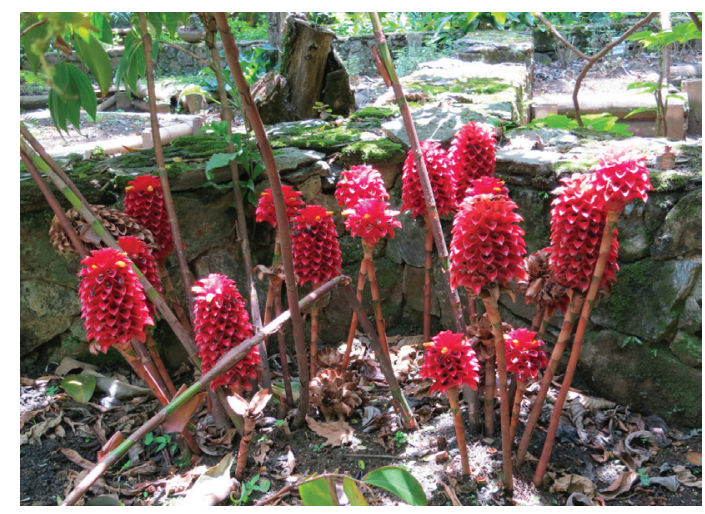

Tapeinochilus ananasae

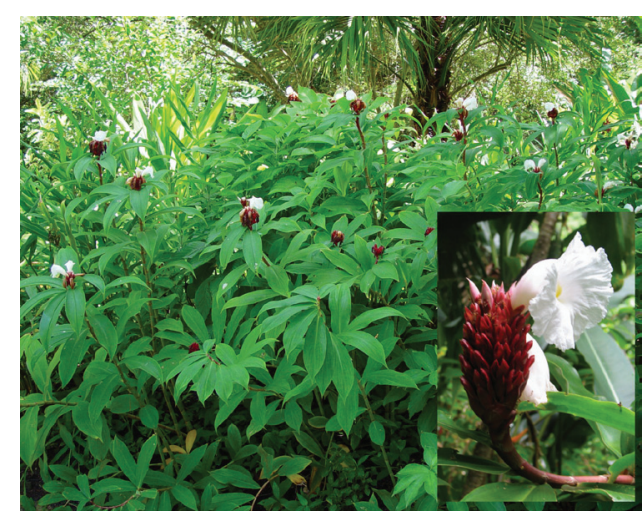

Hellenia speciosa (a/k/a Cheilocostus speciosus)

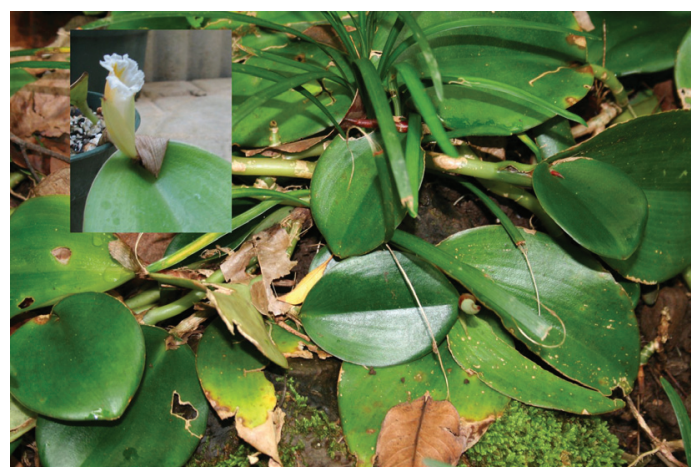

Paracostus englerianus

In the New World there are now delineated four genera. The short growing plants from Brazil and adjoining countries in the genus Chamaecostus is best represented by the popular orange flowering garden plant C. cuspidatus. The very tall, white or yellow flowering plants in the genus Dimerocostus can be identified by the two chambered ovary (vs. three chambers in others). Then there is the short but colorful yellow flowering Monocostus from northern Peru which has but one species - M. uniflorus.

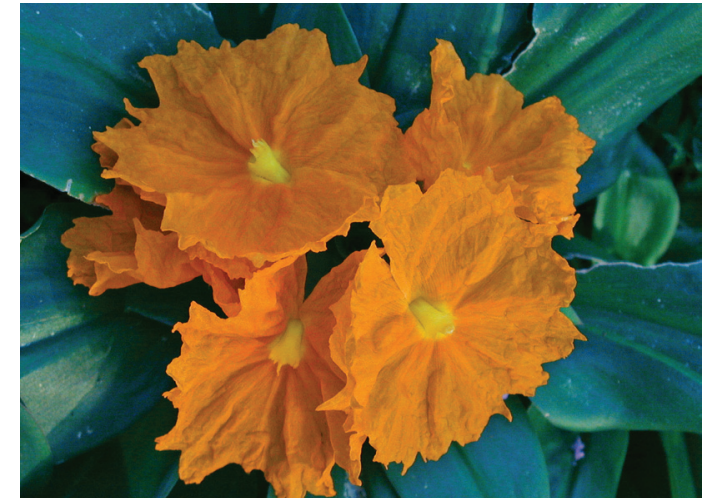

Chamaecostus cuspidatus

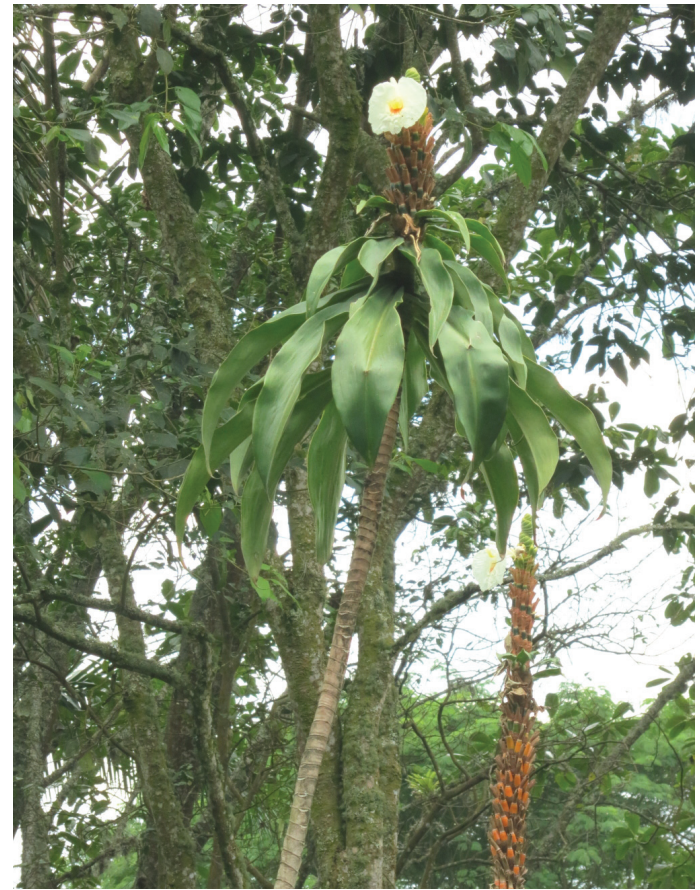

Dimerocostus strobilaceus 


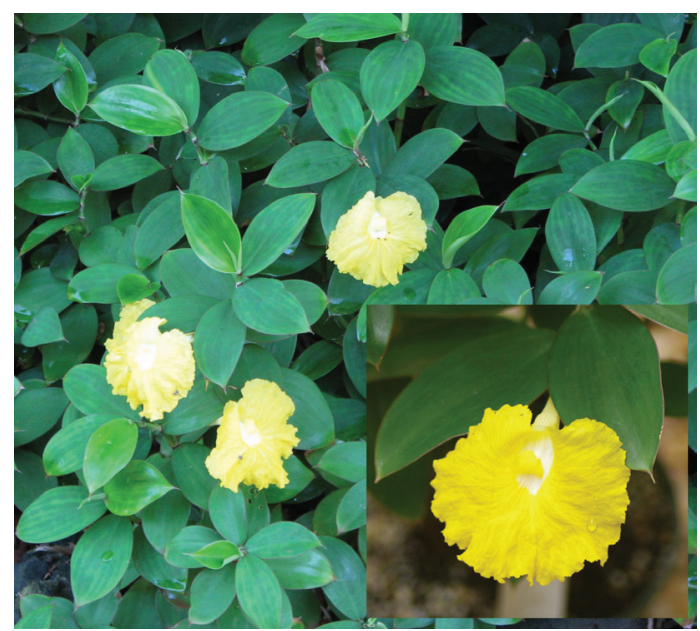

Monocostus uniflorus

This brings us to the subject of this article - the genus Costus which includes species from Africa as well as the New World tropics. Dr. Paul Maas has recently completed a monograph of the African Costus which is soon to be published, and I am not including those plants within the purview of this article as I expect there will be substantial changes to the systematics of those plants.

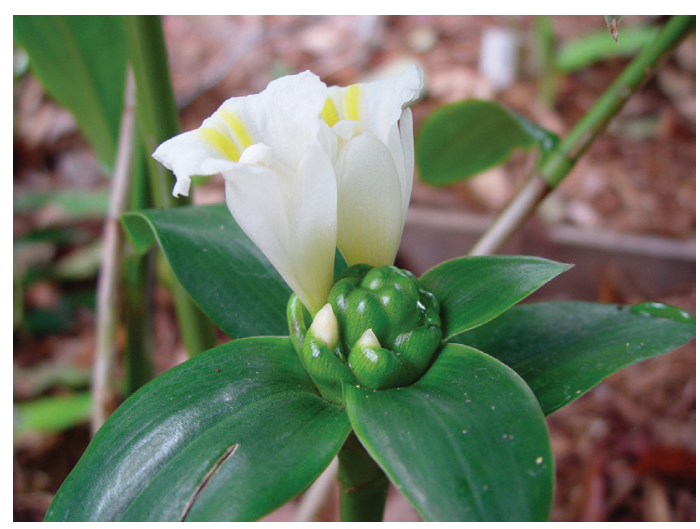

African plant, Costus maculatus

The best source for identification of neo-tropical Costus is the monograph that was prepared by Dr. Paul Maas, published in 1972 in the Flora Neotropica series by the New York Botanical Garden. An update with several additions was published in 1977. Based on this work, I have developed a basic approach I use in trying to narrow down the possibilities for identification.

\section{GROUPINGS OF NEOTROPICAL COSTUS}

The first step is to determine which of the following natural groups the plant fits best in. Photos showing these groups and the Costus that are examples can be found on my website at the following URL: http://www.gingersrus. com/images/Neotropical_Costus.php?columns $=5$ 


\section{Group 1 - Costus with appendaged bracts and tubular flowers}

I am including in this group plants where the bracts are reflexed and curve outwards giving the appearance of having appendages, as well as the plants that have distinct leafy appendages to the bracts. This group is best represented by the commonly cultivated species Costus productus. In this species, the bracts narrow and curve outwards at the apex. Another example in this group is Costus comosus which has a very distinct leafy appendage to the bracts. The flowers in this group are more or less tubular in shape, and it has been theorized that they are adapted to pollination by hummingbirds.

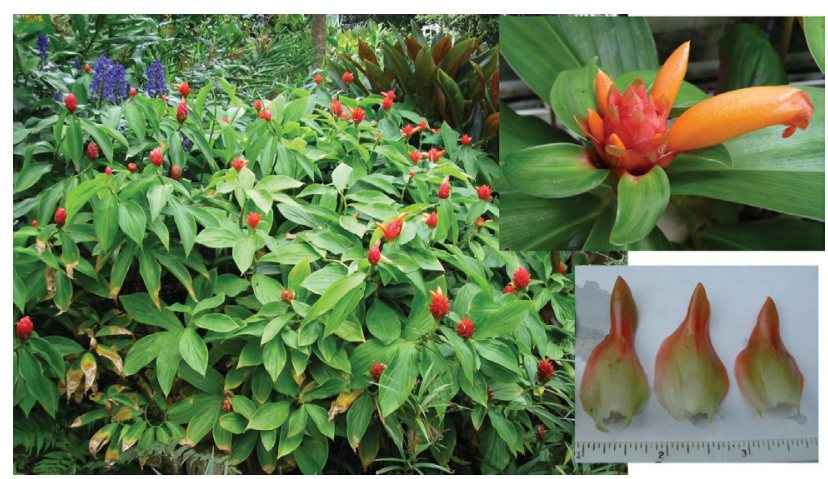

Costus productus

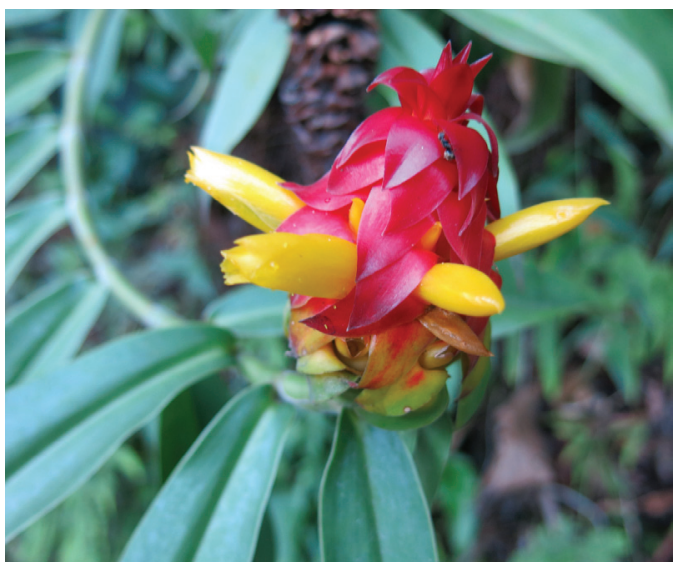

Costus comosus

Group 2 - Costus with appendaged bracts and open flowers

In this group, the bracts have leafy appendages as in group 1, but the flowers have a more open shaped labellum, and most are believed to be pollinated by bees. Costus guanaiensis is a widespread species, occurring in many different forms, that is the most commonly found example of this group.

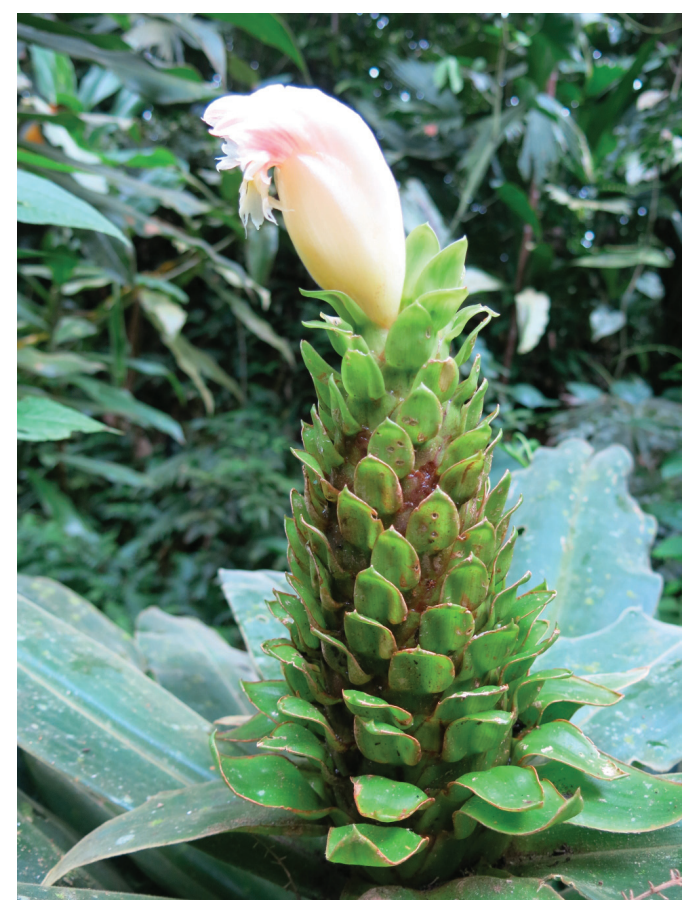

Costus guanaiensis

\section{Group 3 - Costus with non-appendaged bracts and tubular flowers}

In this group, the bracts do not have appendages or only have them on the bracts at the very base of the inflorescence. The bracts form a tight cone. In group 3, as in group 1, the flowers are more or less tubular in shape. In this group, the most common example is Costus scaber. In Brazil we also have the species Costus spiralis which I distinguish by the vertical ( 0 degree) angle of its flower compared against the 30 degree angle of $C$. scaber from the bracts. 


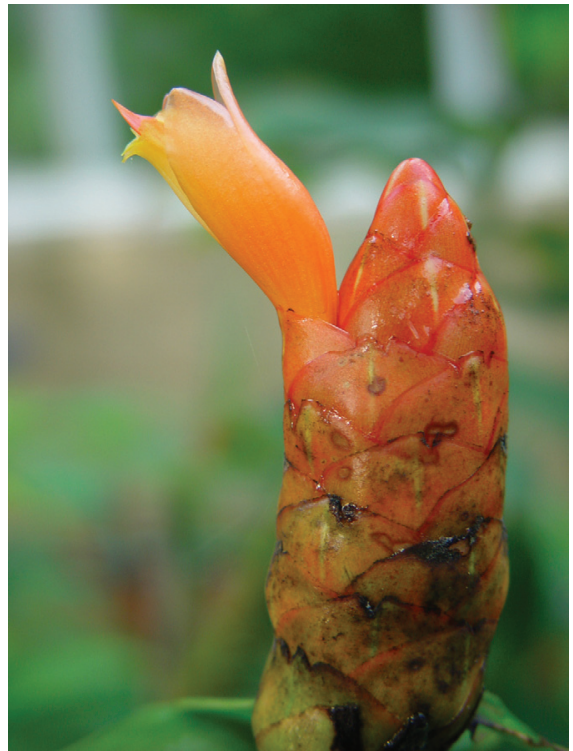

Costus scaber

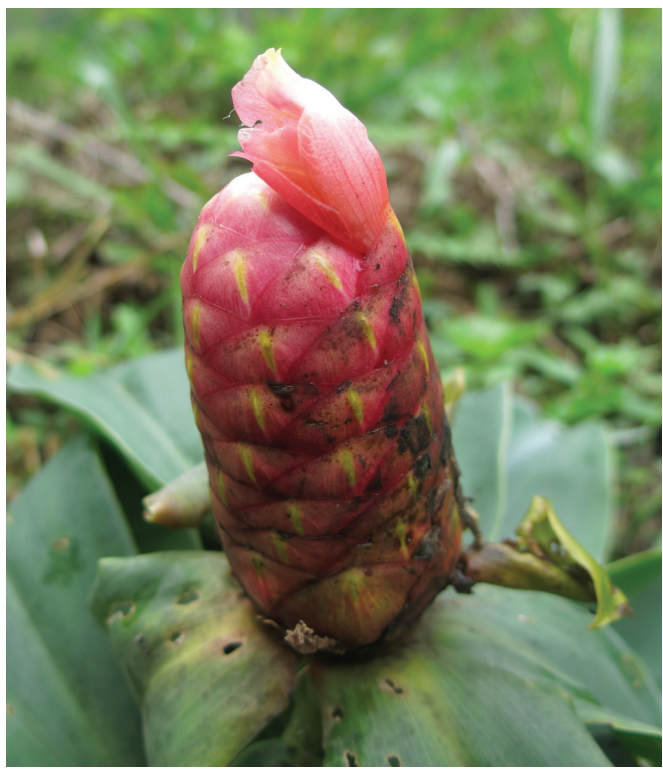

Costus spiralis

\section{Group 4 - Costus with non-appendaged bracts and open flowers}

In this group the bracts also form a tight cone, but the flowers have the more open type labellum. The type species of the genus, Costus arabicus, is an example of this group. Another common and widespread example is Costus laevis.

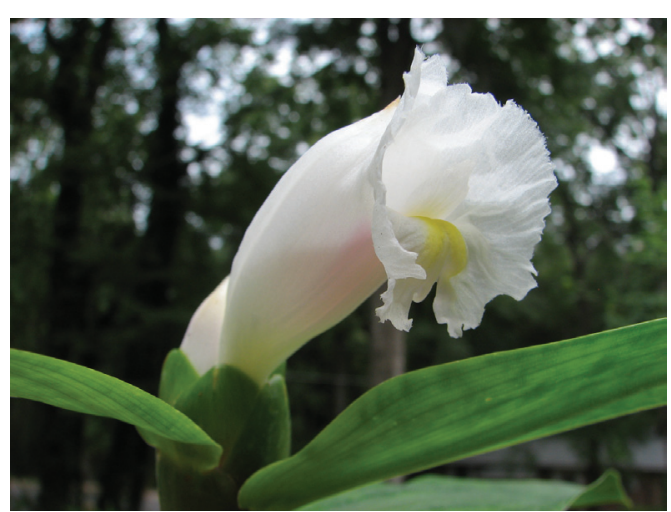

Costus arabicus

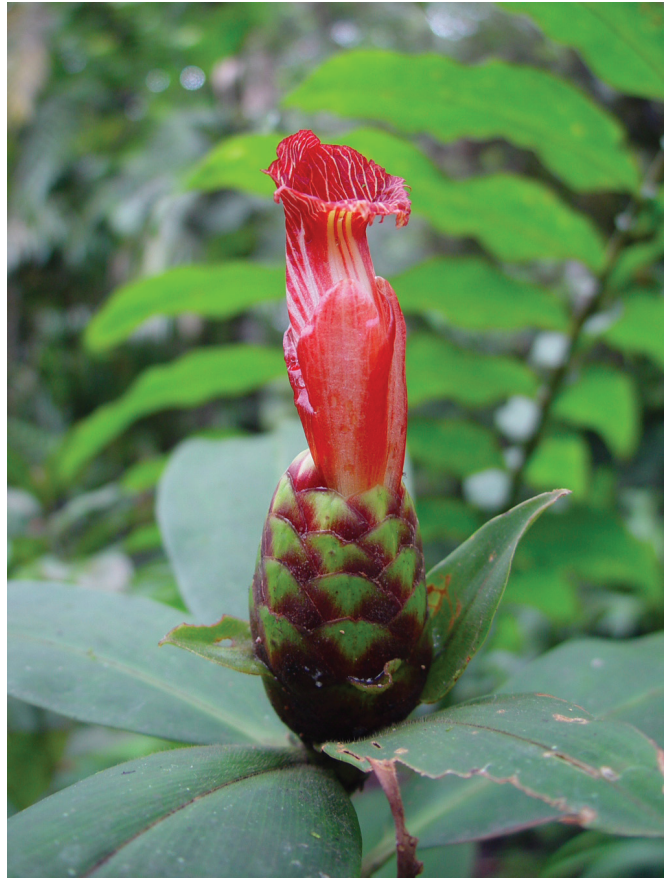

Costus laevis
Once you have determined which group your plant fits into, you can then use Dr. Maas' plant key and descriptions to apply other morphological characters and further narrow down the possibilities. The most important of these characters, are those that tend to be consistent within a given species. 
Ligule length and shape. Measure the length of the ligule from the base of the leaf petiole to the top margin. The shape is also important. Some have one or two lobes while other species have ligules that are of even length around the sheath (truncate as described by Maas).
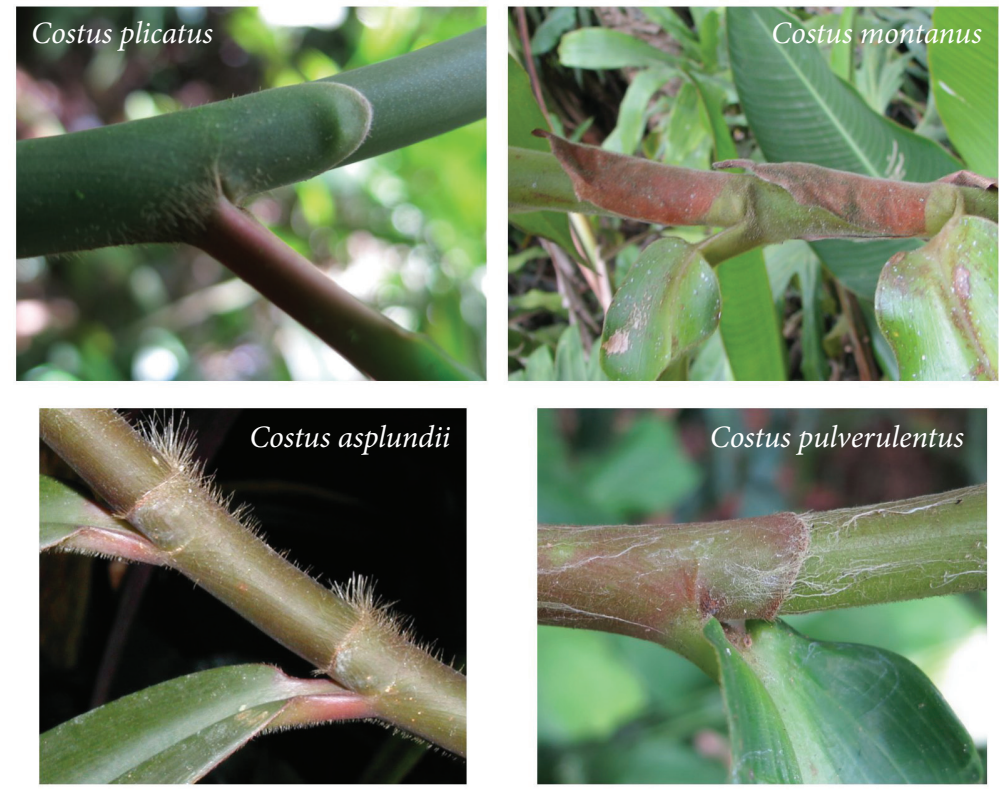

Examples of ligules.

Length of various internal parts of the inflorescence, such as the bracteole and calyx. In some species the bracteole is very long and the calyx may be long and deeply tri-lobed. Other species have a very short calyx with shallow lobes.

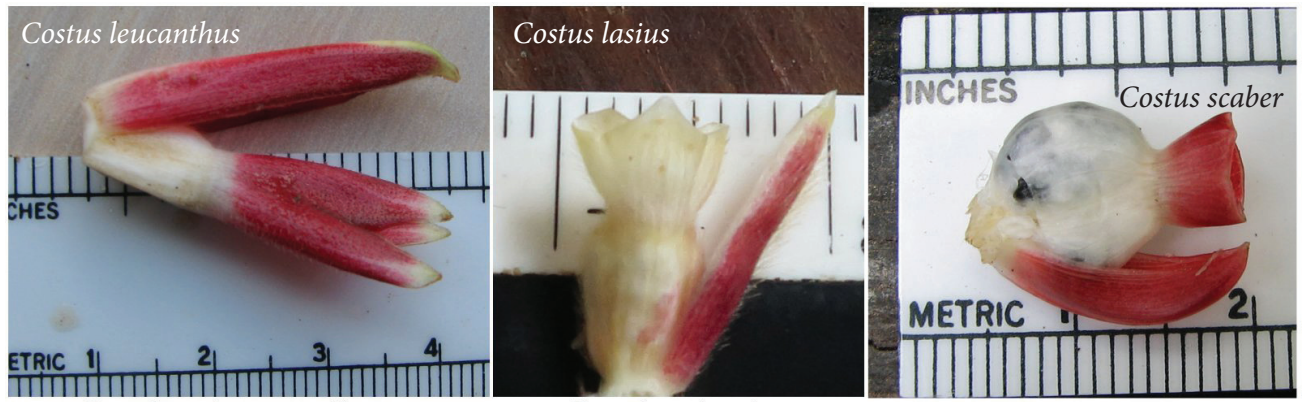

Examples of bracteoles and calyx

The edges of the bracts, whether they are smooth (entire) or fibrous. This character is important in the identification of some species such as Costus amazonicus or Costus pulverulentus.

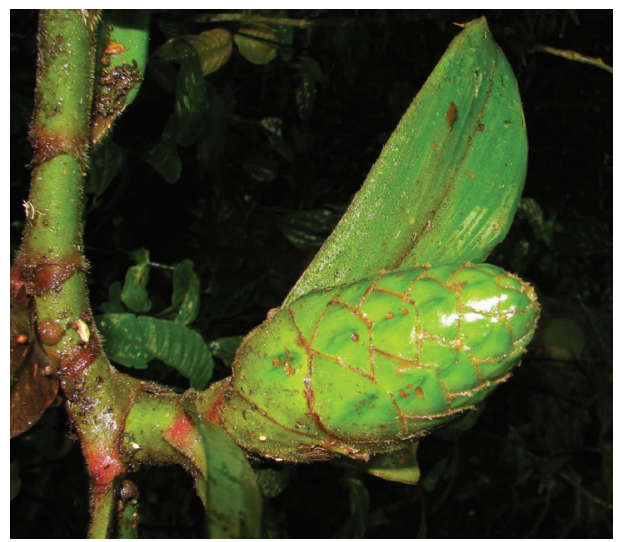

Fibrous bract margins of Costus amazonicus 
One characteristic that I have found NOT to be particularly useful is the position of the inflorescence either terminal or basal. It is true that a given species will normally flower one way or the other, but I have seen far too many examples where a given species will flower both ways, and sometimes on the same plant.
This fact has been recognized in Dr. Maas' identification key, but I have found in nature several more examples of this that were not recognized in the key. Accordingly, I do not give a lot of weight to this factor in identifying an unknown plant - especially when it is not a clone of a cultivated plant.

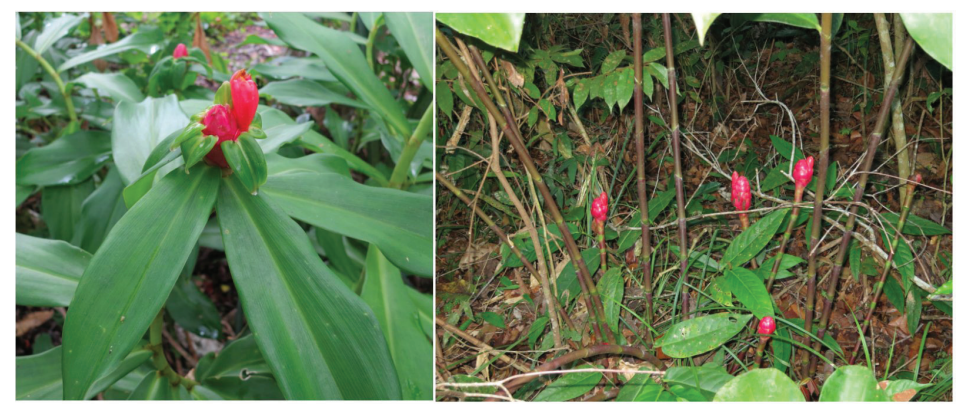

Costus spiralis with terminal and basal flowering (Cristalino, Brazil)

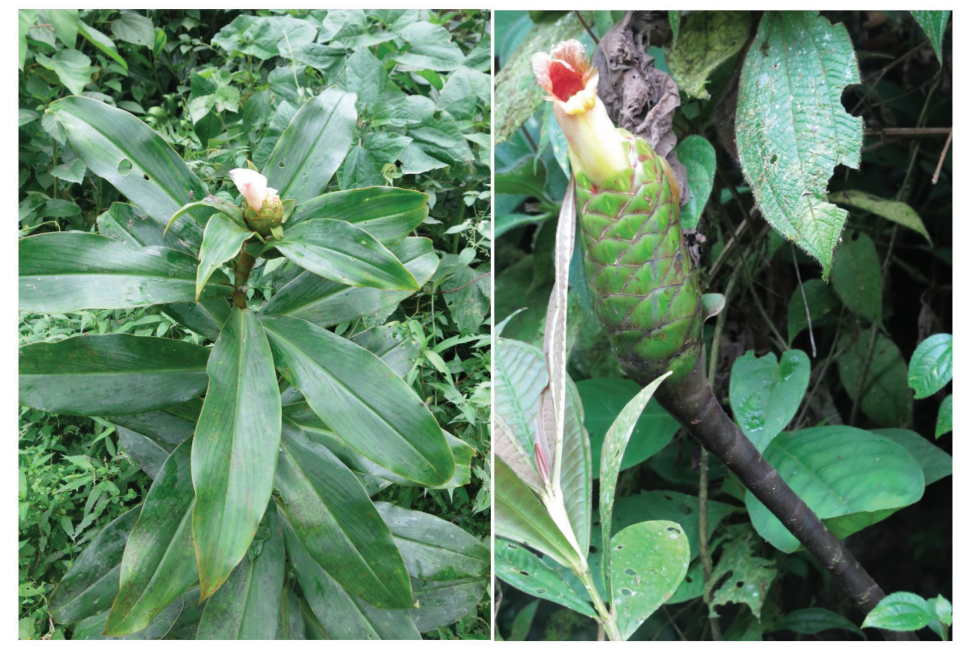

Costus amazonicus with terminal and basal flowering (southern Ecuador)

Another important aid in identification is the geographical origin of the plant in question. There are many very similar-looking Costus that are difficult to distinguish by their outward appearance, but can be identified based on the region or even by the habitat in which they are growing. This information may not be available for a questioned plant that is in cultivation, but should certainly be considered if known.

\section{4, CULTIVATED PLANTS OFTEN INCORRECTLY IDENTIFIED}

Costus comosus var. bakeri vs. Costus barbatus The plant known by the common name of the "red tower ginger" is often incorrectly listed as "Costus barbatus".
This plant is actually a form of Costus comosus and is usually correctly listed as such in Australia, but not in the USA and many other countries. If you see a plant in a botanical garden or nursery that is tagged as "Costus barbatus" it is probably the cultivated form of "Costus comosus".

The true species Costus barbatus is endemic to the Central Valley area of Costa Rica and is not found in cultivation. It differs from the cultivated plant known incorrectly under that name by its much longer ligules and its pubescent flowers among other differences. For years I searched for this species and finally found it in 2011 growing in a creek bed in a forest patch east of San Jose, Costa Rica. I have only seen it at one other location and it is Red Listed as a critically endangered species. 

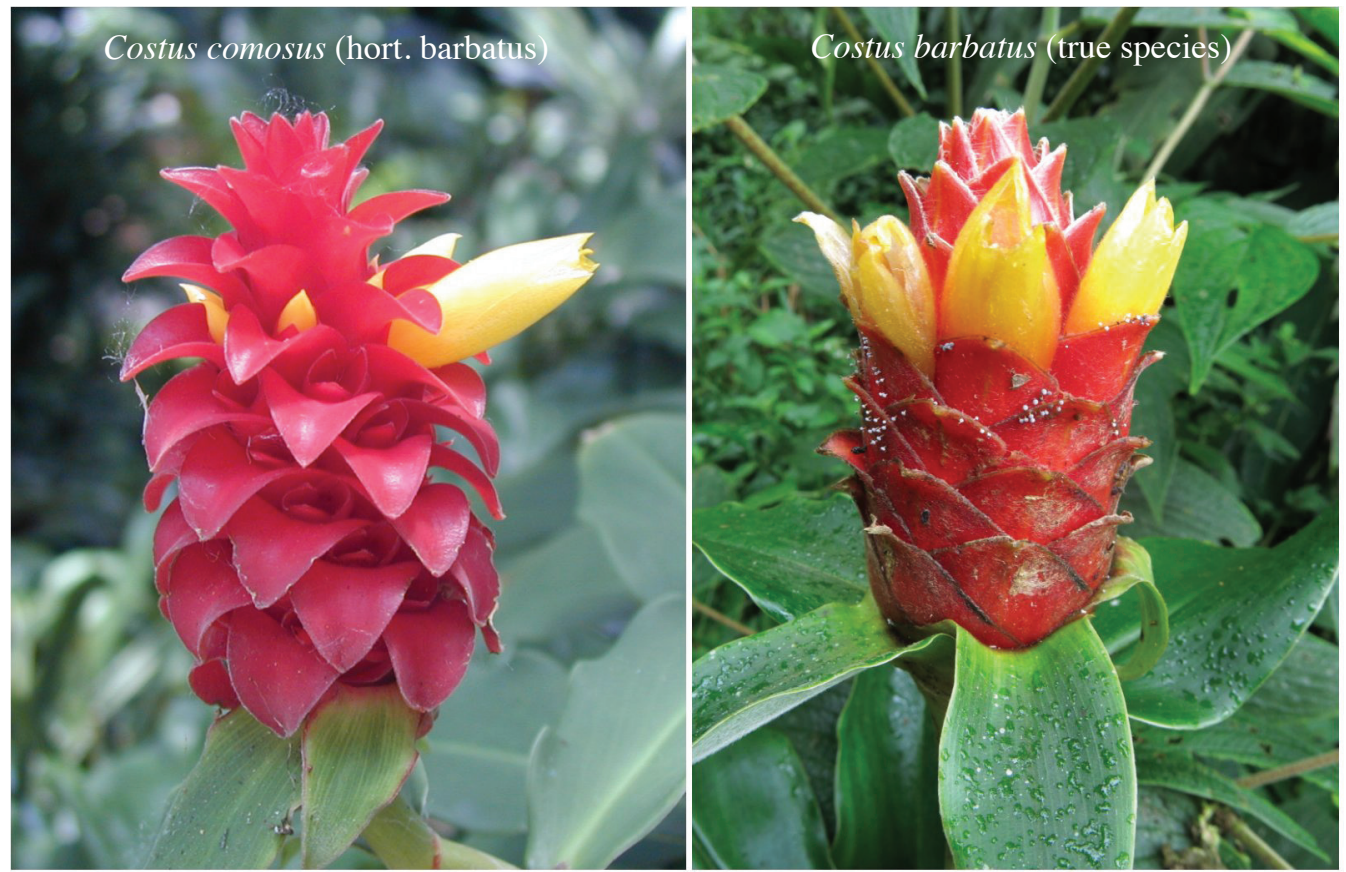

Comparison of true species Costus barbatus with horticultural plant sold under that name.

\section{Costus scaber vs. Costus spicatus}

Another cultivated plant that is sometimes incorrectly named is the indianhead ginger, which is sometimes listed as Costus spicatus. The anatomical differences between the two species are difficult to detect and involve the size of internal parts of the inflorescence - the bracteole and calyx. The bract color of $C$. spicatus is usually greenish on the exposed parts in contrast to the reds and oranges of $C$. scaber or $C$. spiralis. In nature it is much easier to ascertain because the natural range of Costus spicatus is limited to certain Caribbean islands whereas $C$. scaber is found over a wider range throughout most of the American tropics.
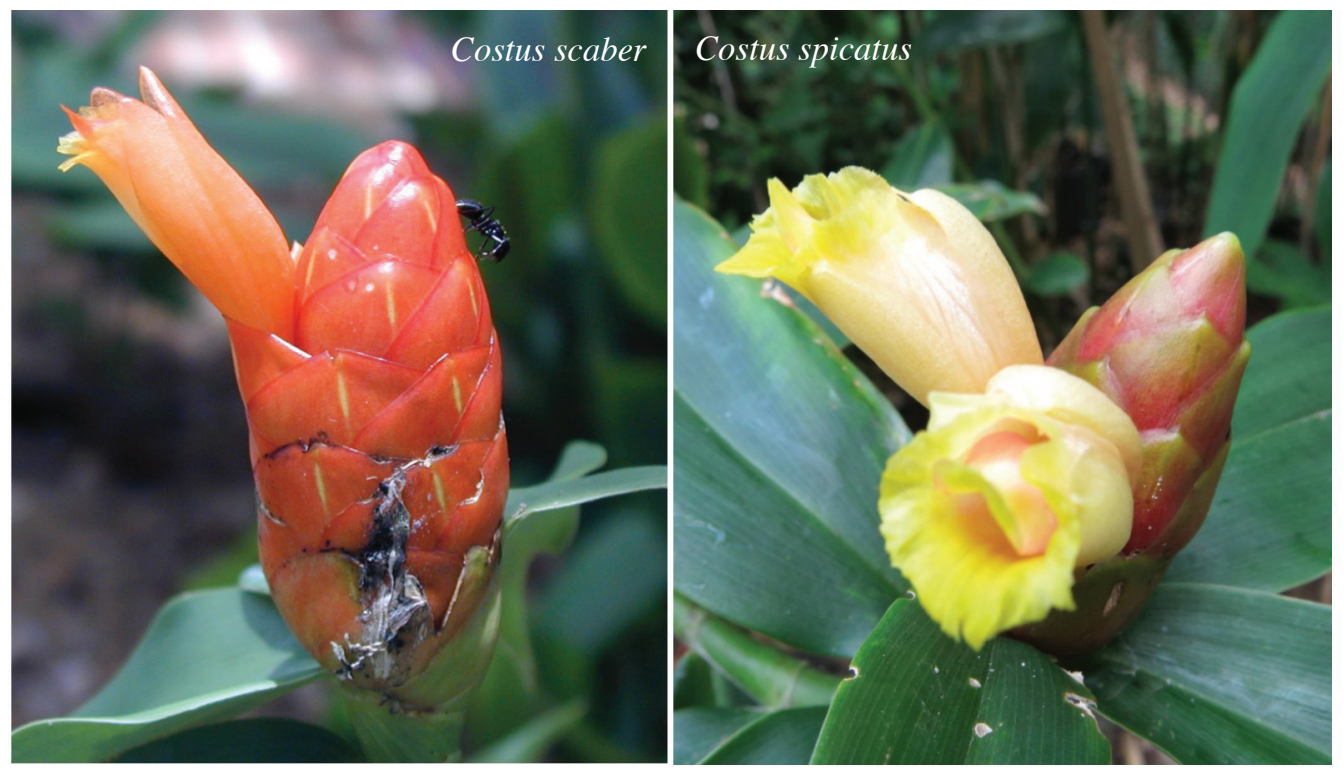

Comparison of true species Costus spicatus with horticultural form of Costus scaber 


\section{Costus amazonicus vs. Costus arabicus variegated}

For many years the variegated, white flowered plant in the photo below has been tagged incorrectly as Costus amazonicus. The true $C$. amazonicus has fibrous margins to the bracts and does not branch along the stems as does the variegated plant, which is actually a form of Costus arabicus.

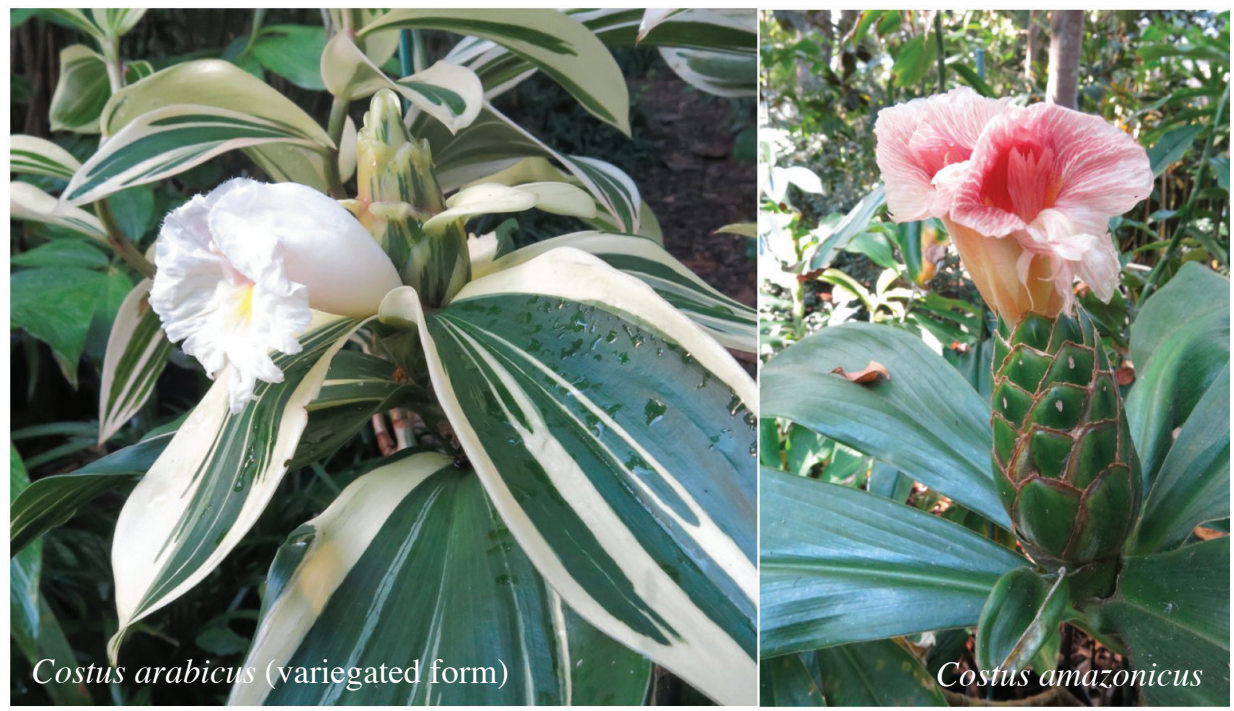

Comparison of true species Costus amazonicus with variegated form of Costus arabicus

\section{Costus productus vs. Costus curvibracteatus}

The short statured plant common in cultivation shown below is sometimes incorrectly tagged as C. curvibracteatus (from Costa Rica and Panama) but it is actually the Peruvian species $C$. productus. It has longer ligules and typically is a much shorter growing plant.
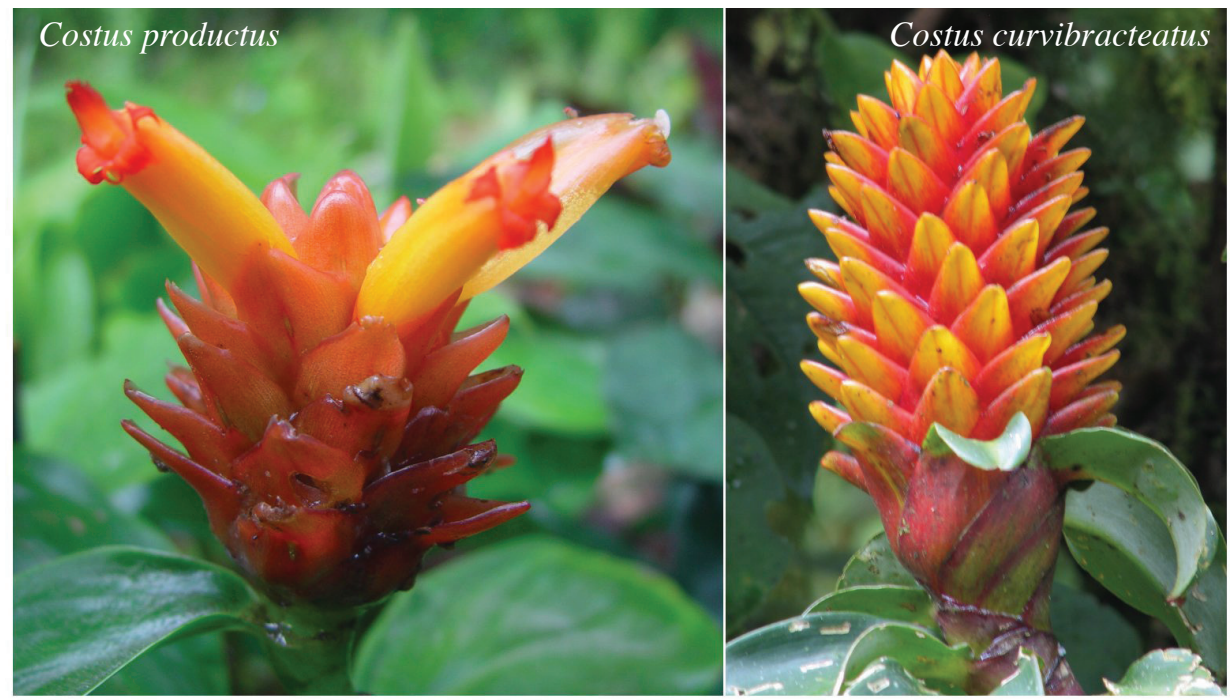

Comparison of true species Costus curvibracteatus with horticultural form of Costus productus

\section{HARDY COSTUS SPECIES IN CULTIVATION}

In regions where the winter temperatures fall below freezing, most Costus must be protected or grown in a greenhouse. Such is the case in my garden in Tallahassee,
Florida, USA, which is USDA zone 8B. Here the winter temperatures fall well below freezing with nighttime temperatures often down to $-7^{\circ}$ Celsius $\left(20^{\circ} \mathrm{F}\right)$. The following species have been well tested here for winter hardiness. 
Costus pictus - This species is found in cultivation in two distinct forms. One form is the 'Heiroglyphics' form with the pattern on the stems. The other form is known in Puerto Rico as the "planta insulina". Both forms are quite hardy and will survive over winter where temperatures drop well below freezing and will come back strong and flower over the summer.

Costus scaber - It is not known whether all forms of this species are cold hardy, but the plant common in cultivation as the "indianhead ginger" is perfectly hardy in areas with temperatures matching the USDA Zone 8.

Costus comosus - Here I am referring to the cultivated plant that is sometimes incorrectly tagged as Costus barbatus. This plant is cold hardy but seldom will flower if it has frozen back to the ground over winter. The Tim Chapman hybrid 'Phoenix' as mentioned below is also hardy much more free-flowering.

Costus productus - I have had some success with this plant surviving freezing temperatures in my garden, but not as reliable as the others listed here.

Cheilocostus (now Hellenia) speciosus and lacerus. The common ornamental garden "costus" with the white flowers (C. speciosus or H. speciosus) is an Asian plant. Some forms from monsoonal areas are quite cold hardy and some forms that are evergreen in nature are not so hardy. The form in my garden came from the Norfolk Botanical Garden (Norfolk, Virginia, USA) and is reliable here. A very similar looking species is C. lacerus, which is also hardy here.

\section{COSTUS HYBRIDS AND CULTIVARS}

There have been a number of new hybrids and cultivars placed into cultivation in recent years. The Heliconia Society International is the International Cultivar Registration Authority (ICRA) for Costus and many of these new cultivars have been officially registered following the rules of the International Society for Horticultural Science (ISHS). Photos and details can be found on the Heliconia Society website at http://www.heliconia.org/costus.

My personal favorites include Costus 'Phoenix', a hybrid developed by Tim Chapman using Costus comosus with Costus productus to produce a somewhat cold hardy hybrid that looks like the horticulture plant incorrectly known as Costus barbatus, but it flowers much more prolifically, both terminally and at the base of the plant.

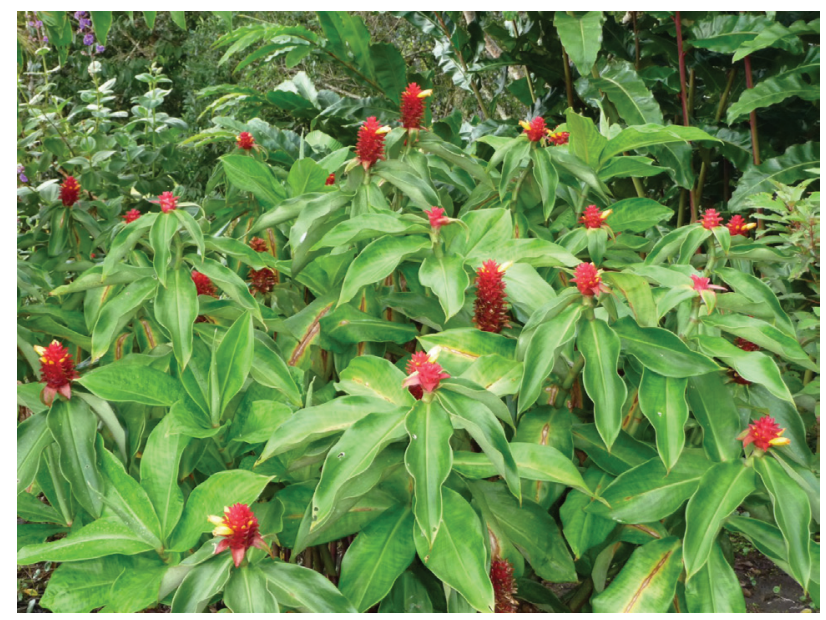

Costus hybrid 'Phoenix'

Of my own hybrids, my favorite is Costus 'Moonluster', which I bred from the 'Sweet Charlotte' form of Costus guanaiensis with Costus 'Belize Yellow'. It is also fairly cold hardy and produces prolific flowering both terminal and basal on a compact plant about $11 / 2$ meters tall. 


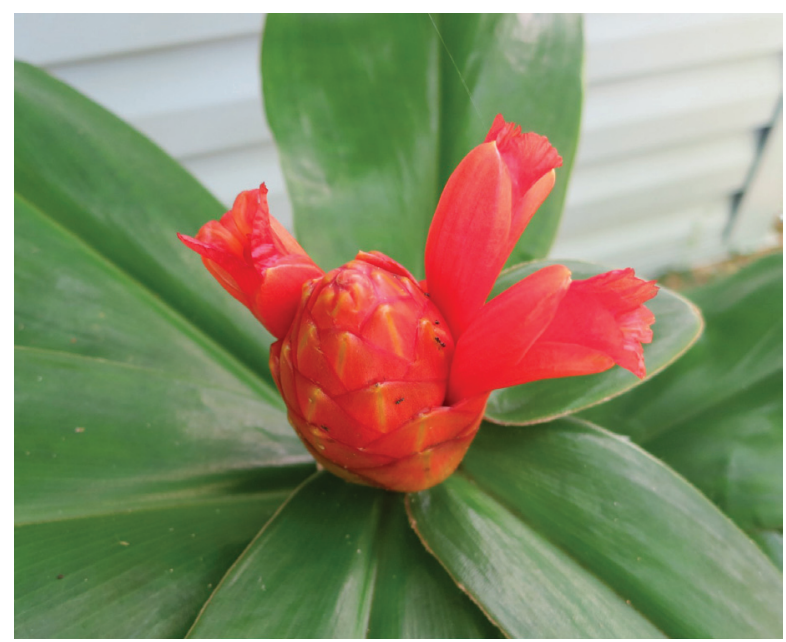

Costus hybrid 'Moonluster'

Another great cultivar is a natural hybrid I found in the mountains of Costa Rica and have named Costus 'Mellow Yellow'. It is believed to be a hybrid of Costus wilsonii with Costus villosissimus. Once established it flowers year round and produces very showy yellow flowers much like the parent $C$. villosissimus.

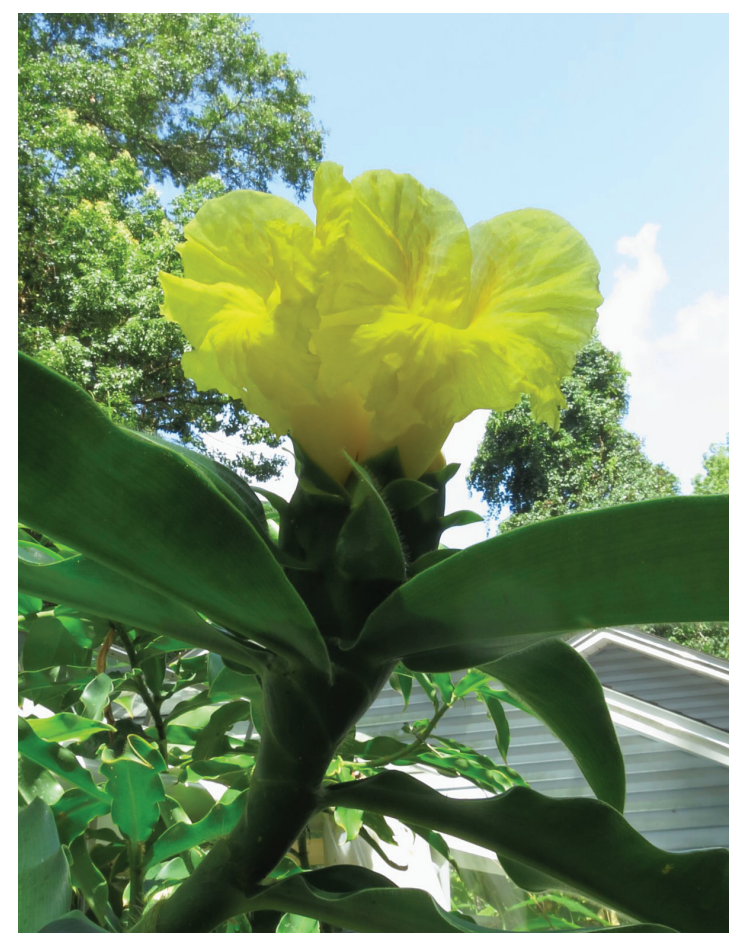

Costus cultivar 'Mellow Yellow'

\section{ADDITIONAL INFORMATION}

Much more information about the plant family Costaceae can be found on my website at http://www. gingersrus.com. There are plant datasheets for all seven genera, identification photos, an identifier tool, and detailed botanical descriptions of most species of neo-tropical Costus.

My field observations of Costus with additional photographs can be found at http://www.inaturalist.org/ observations/selvadero .
Paul Maas’ 1972 and 1977 monographs on neo-tropical Costaceae can still be found through some on-line used book distributors. Look for Flora Neotropica Monograph No. 8 and Flora Neotropica Monograph No. 18, published by the New York Botanical Garden.

Registered Costus cultivars can be found on the Heliconia Society website at http://www.heliconia.org/costus. Back issues of the quarterly Bulletin can also be found on the Heliconia Society website, including articles on a. Costus of the Golfo Dulce (Costa Rica); b. Natural hybridization of Costus; c. The re-discovery of Costus barbatus; d. Search for Costus zamoranus; and e. Search for Costus vinosus. 